\title{
An optimized configuration of adsorptive wells for the remediation of an aquifer contaminated by multiple aromatic hydrocarbon pollutants
}

\author{
I. Bortone ${ }^{*}$, S. Chianese ${ }^{2}$, A. Erto ${ }^{3}$, A. Di Nardo $^{2}$, C. De Crescenzo², D. Karatza ${ }^{2}$, G.F. \\ Santonastaso $^{2}$, D. Musmarra ${ }^{2}$
}

${ }^{1}$ School of Water, Energy and Environment, Cranfield University, Cranfield, MK43 0AL, UK

${ }^{2}$ Dipartimento di Ingegneria, Università degli Studi della Campania "Luigi Vanvitelli”, Via Roma 29, 81031 Aversa (CE), Italy

${ }^{3}$ Dipartimento di Ingegneria Chimica, dei Materiali e della Produzione Industriale, Università di Napoli Federico II, 80125, Napoli, Italy

*Corresponding author: I. Bortone, e-mail: imma.bortone@cranfield.ac.uk, tel +44 1234754819

\begin{abstract}
Adsorptive wells arrays are an innovative outline of Permeable Reactive Barrier (PRBs) made of a definite number of passive deep wells opportunely distributed in the aquifer, known as PAB-D (Discontinuous Permeable Adsorptive Barrier). They are generally located downstream the contaminated groundwater flow and perpendicularly to the groundwater flow direction. Being PABD wells filled with adsorbing media, whose hydraulic permeability is higher than the surrounding media, the array will create a targeted capture zone, which will force the contaminated water to pass through the whole PAB-D, allowing for both the interception of the contaminant plume and its treatment. In this work, an optimized configuration of PAB-D is presented, for the in situ-remediation of an aquifer simultaneously contaminated by benzene and toluene. The design optimization of the PAB-D was performed by using COMSOL Multiphysics ${ }^{\circledR}$, in which numerical simulations reproduced the transport and the adsorptive phenomena occurring inside the aquifer and the barrier itself. The proposed technique was applied to the remediation of an aquifer located in an urban area in the north of Naples (Italy), in proximity of numerous landfills, where the contamination was spread over an area of $0.10 \mathrm{~km}^{2}$. Simulation results confirm the effectiveness of the PAB-D, being both pollutant plumes intercepted and their concentrations reduced below their correspondent Italian regulatory threshold values. The best array configuration of PAB-D resulted made of 741 wells, each
\end{abstract}


having a diameter of $0.6 \mathrm{~m}$, which was also compared with a continuous barrier (PAB-C) showing a reduction of about $49 \%$ of the volume and $35 \%$ of the overall remediation cost.

Keywords: groundwater remediation; permeable adsorptive barrier; optimization; PRB; organic pollutant removal.

\section{Introduction}

Aromatic hydrocarbons, better known as BTEX (benzene, toluene, ethylbenzene and xylenes), are classified as priority pollutants (US EPA, 1986). Being highly water soluble and volatile, and as a consequence highly mobile in the soil and groundwater environment (IARC, 2013), they are currently considered as among the most serious dangers for groundwater (Mitra and Roy, 2011).

Among BTEX, benzene and toluene are of major concern. They are widely used as industrial solvents and the most detected contaminants found in groundwater especially from landfills, generally resulting from leachate (Caetano et al., 2017; Carpenter et al., 2012; Lahvis et al., 1999). The toxic properties of benzene have been acknowledged since long time (ATSDR, 2007). In fact, it is listed in the $1^{\text {st }}$ group of agents that are carcinogenic to humans by the International Agency for Research on Cancer, while toluene is listed in the $3^{\text {rd }}$ group of agents, and is therefore recognised as being less toxic. However, toluene is still dangerous to humans as there is no antidote to toluene poisoning, and it happens to be the most commonly misused solvent (ATSDR, 2015).

Maximum contaminant levels for groundwater are very strict and established worldwide; for instance, in Italy the regulatory limits are set to 1 and $15 \mu \mathrm{g} \mathrm{L^{-1 }}$ for benzene and toluene, respectively (LD, 2006). Consequently, the removal of benzene and toluene from polluted groundwater is, an essential duty and the development of remediation methodologies, which can provide a sustainable and simple removal of these compounds, is of great interest.

Several technologies, both ex-situ and in-situ, have been investigated and have evolved over the years to clean up contamination from such compounds (Canzano et al., 2014). Ex-situ technologies generally embrace pump and treat methods (P\&T), which can be combined with a physical 
containment of the polluted water by installing slurry walls or some other permanent structure (Brauner and Killingstad, 1996). However, in some cases, being BTEX contamination very persistent through the soil and groundwater, ex-situ treatments can be financially impracticable, and replaced by in-situ methods, which can offer lower costs, less disruption to the surface, and more effective treatment (Bortone et al., 2015; Cole, 1994). In this contest, Permeable Reactive Barriers (PRBs) are a well-regarded passive technique for groundwater remediation, on behalf of their high efficiency, low operating and maintenance costs, especially when dealing with high volume aquifers and low pollutant concentrations (Luo et al., 2016; Bortone et al., 2013a; Powell et al., 1998). Various studies have demonstrated, by comparing PRB with P\&T, a 40-70\% cost saving for groundwater remediation from chlorinated hydrocarbons over extended time periods (Polonski et al., 2017; Reeter et al., 1999). In addition, PRB optimization can help to evaluate and enhance the remediation process to ensure that the environment and, thus, human health are long-term protected at minimum risk and cost. PRB decontamination technique essentially consists in a permeable wall, installed downstream of the aquifer contamination and perpendicularly to the groundwater flow (Liu et al., 2017; Santonastaso et al. 2016). By filling PRBs with a reactive material, more permeable than the surrounding soils, it is possible to simultaneously intercept and degrade, immobilize or adsorb the contaminants, while the groundwater naturally flows under the local hydraulic gradient (Santonastaso et al., 2018a; Thiruvenkatachari et al., 2008). Besides, it can be applied for both in-situ and ex-situ treatments too, as in the "Treat" phase of the P\&T technique (Canzano et al., 2014), and in in-situ treatments, by PRBs.

The filling reactive material is chosen according to the type of contaminants to be removed. Iron metal, $\mathrm{Fe}^{(0)}$, is mainly used as a reactive media of PRBs acting by converting the contaminants, such as chlorophenols, nitrates and chlorinated hydrocarbons to non-toxic or immobile species (Lee et al., 2017; Gao et al., 2015; Chen et al. , 2011). Organic materials are, instead, among the best reactive media to promote biological process for the remediation of other contaminants, such as nitrate and sulphate (Powell et al., 1998). Oxidation processes can be also applied (EPA, 1993). However some 
studies, assessing the potency of different liquid oxidants, have highlighted how higher dosages of such substances could cause negative effects and harm their removal efficiency (Chen et al., 2016). Activated carbon is proven to be a valid alternative and very efficient for aromatic hydrocarbon adsorption also when a multiple contamination occurs, showing a good compatibility with natural environment (Leone et al., 2018; Erto et al., 2014; Liang and Chen, 2010).

PRBs made of adsorbing materials are usually referred as Permeable Adsorptive Barriers (PABs) (Bortone et al., 2015; Erto et al., 2014; Powell et al. 1998).

In this work, the results of an optimized configuration of PAB, called discontinuous permeable adsorptive barrier (PAB-D), are presented for an in-situ remediation of an aquifer at the same time contaminated by both benzene and toluene. A PAB-D is an innovative outline of permeable adsorptive barrier composed by one or more arrays of deep "unpumped" wells, filled with adsorbing material. Such configuration can be easier and cheaper to build and allows to remediate the same volume of groundwater with smaller amount of adsorbing material (Santonastaso et al., 2018a).

The design and optimization of a PAB-D consists mainly in: i) the definition of the well grid (i.e. number and position of wells), ii) optimization of its geometrical parameters such as the well diameter, the well-to-well distance, the number of well columns in the grid and the column-to-column distance (Santonastaso et al., 2018a; 2018b; Bortone et al., 2015) The optimal PAB-D design was carried out by using a numerical 2D model developed in COMSOL Multiphysics ${ }^{\circledR}$ environment, in which a finite element approach is used (Tabatabain, 2014; Prior, 2011). Numerical simulations predicted the pollutants fate and transport within the aquifer and the adsorption phenomena occurring onto the material of the wells.

The investigated aquifer is located in a metropolitan area in the north of Naples (Italy), where benzene and toluene were the main two BTEX components with significant concentrations compared to the Italian regulatory limits set for groundwater. The benzene/toluene adsorption isotherm in binary system was previously determined via laboratory tests (Erto et al., 2017). A set of numerical simulations was carried out by including both the aquifer and adsorbing media characteristics in a 
unique framework and by testing the performance of different PAB-D configurations for its optimization. Finally, a comparison between a continuous PAB and the optimal PAB-D well array was performed and applied to the same case study, with the aim to decide on the most convenient technology in terms of both total volume of adsorbing material and remediation costs.

\section{Materials and methods}

A finite-element model in COMSOL Multiphysics ${ }^{\odot}$ allowed to simulate both groundwater and contaminant flows in the case study aquifer.

The PAB-D design prerequisites are a series of preliminary studies and site investigations, aimed at acquiring information about the hydraulic and geotechnical properties (i.e. groundwater depth and thickness, groundwater flow direction and hydraulic heads, hydraulic conductivity and porosity of the different hydrological layers, etc.), as well as the aquifer state of contamination in terms of pollutant species and plume extent.

A successive step called for a proper PAB-D design procedure in order to follow the array design criteria: this requires the barrier to be orthogonal to the groundwater flow direction and as close as possible to the pollutant plume, for a more effective capture of the plume, with a length able to intercept the whole contaminated water and a height equal to the aquitard thickness (Bortone et al., 2013b).

In order to properly design a PAB-D, it is necessary to define the spatial distribution and geometric characteristics of the well grid, in terms of well diameter, $D_{w}$, well-to-well distance, $I$, line-to-line distance, $d_{c}$, number of well lines in the array, $n_{c}$, orientation of each well line, $\varepsilon$, with groundwater flow direction $\overline{\mathrm{u}}$ and number of wells in each line, $n_{w}$. These parameters are schematized in Figure $1 b$, where there is also a 3D PAB-D representation (Figure 1a). 


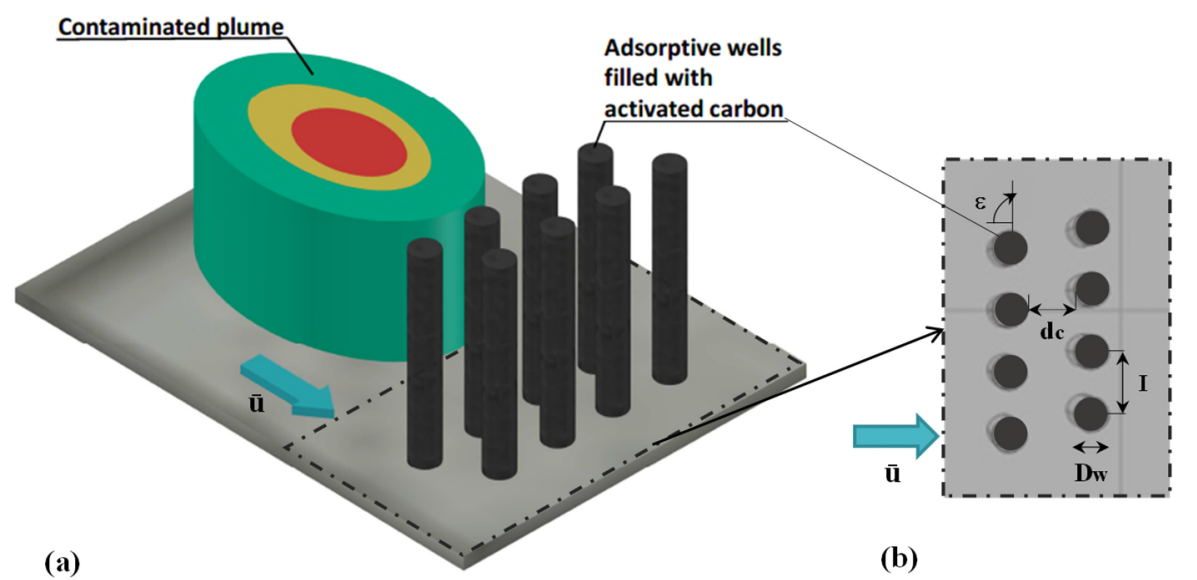

Figure 1. PAB-D schematization (a) with main design parameters representation (b).

The computational domain was schematised as a 2D system, as along the vertical groundwater direction (z-direction) the concentrations of contaminants and the medium properties are assumed as constant (Figure 1a).

The mathematical model, reproducing the transport phenomena of the pollutants, the groundwater flow through the PAB-D and the adsorption occurring inside the barrier, can be described by the following equations (Bear, 1979):

$$
\frac{\partial}{\partial t}\left(C_{i}\right)+\frac{\nabla\left(C_{i} \cdot \vec{u}\right)}{n}=\nabla\left(D_{h, i} \cdot \nabla C_{i}\right)+R_{i}
$$

in which $n$ is the porosity of the site; $C_{i}$ is the concentration of the species $i ; \vec{u}$ is the unit flux vector; $R_{i}$ is reaction terms of species $i$; and $D_{h . i}$ is the hydrodynamic dispersion coefficient, expressed as in the following (Gelhar et al., 1992):

$$
D_{h, i}=D_{i}+D_{d, i}^{*}
$$

where $D_{i}$ and $D_{d, i}^{*}$ are the tensor of the mechanical dispersion and the coefficient of molecular diffusion (a scalar) of the species $i$, respectively.

The components of the mechanical dispersion tensor are: 
$D_{x x}=\alpha_{L} u_{x}^{2} /|u|+\alpha_{T} u_{y}^{2} /|u|$

$D_{y y}=\alpha_{L} u_{y}^{2} /|u|+\alpha_{T} u_{x}^{2} /|u|$

$D_{x y}=D_{y x}=\left(\alpha_{L}-\alpha_{T}\right) u_{x} u_{y} /|u|$

where $\alpha_{L}$ and $\alpha_{T}$ are the longitudinal and transverse dispersivities, respectively, and depend on the porosity and tortuosity of a particular soil. Longitudinal dispersivity requires to be experimentally obtained for the fluid, contaminant and concentration, while transverse dispersivity typically follow the relationship given by (4).

$\alpha_{L}=10 \alpha_{T}$

The first left-hand term of Eq. (1) represents the accumulation of species $i$ within the liquid; the second term describes the convection phenomena due to the groundwater flow. On the right-hand side of Eq. (1), the first term introduces the spreading of species $i$ due to hydrodynamic mixing dispersion and the last term can be specified as it follows:

$R_{i}=\frac{\rho_{b}}{n_{b}} \frac{\partial \omega}{\partial t}=k_{c, i} a\left(C_{i}-C_{i}^{*}\right)$

In Eq. (5), $\rho_{b}$ and $n_{b}$ are the bulk density and porosity of the adsorbing material, respectively, $k_{c, i}$ is the mass transfer coefficient for the adsorption of the species $i, a$ is the specific surface area of adsorbent particles and $C_{i} *$ is the concentration of the species $i$ in the liquid phase at thermodynamic equilibrium with the concentration on the adsorbent solid (i.e. the solid adsorption capacity, $\omega$, obtained from the adsorption isotherm of the species $i$ on the chosen adsorbent). The equilibrium concentration of species $i$ between solid and liquid phases can be described by several multicomponent adsorption models, whose complexity depends on the physical adsorption mechanism assumed (Erto et al., 2017).

For low concentration values of the compounds, as in the case of the area of investigation presented in this study, the adsorption phenomena can be described by multicomponent Langmuir model: 
$\omega_{i}=\omega_{i, M A X} \frac{K_{i} C_{i}^{*}}{1+\sum_{i}^{m} K_{i} C_{i}^{*}}$

where $\omega_{i}$ is the adsorption capacity of species $i, \omega_{i, M A X}$ is the correspondent maximum value, $m$ the number of compounds and $C^{*}{ }_{i}$ and $K_{i}$ are respectively the equilibrium concentration and adsorption constant of species $i$.

The unit flux vector in Eq. (1) can be calculated via the Darcy equation:

$\vec{u}=-K_{s} \nabla h \quad$ or $\quad \vec{u}=-K_{b} \cdot \bar{\nabla} h$

where $h$ is the hydraulic head while $K_{s}$ the hydraulic soil conductivity and $K_{b}$ is the barrier hydraulic conductivity. A distribution of the aquifer hydraulic heads was given on all boundaries of the site domain, as obtained for the site investigations (Erto et al., 2011).

The numerical solution of Eqs. (1)-(7) was performed by using COMSOL Multiphysics pre-defined modules "Darcy's Law" and "Solute Transport" describing the subsurface flow. In particular, Eq. (5) and (6) were implemented via an ad-hoc user-defined physic describing the adsorption and desorption phenomena.

The initial and boundary conditions of the system, via considering a number $i$ of species equal to 2 , were assumed to be:

$$
\begin{aligned}
& \begin{cases}-D_{h, 1} \nabla C_{1}=0 & \mathrm{x}=0 \forall y \forall t \\
-D_{h, 2} \nabla C_{2}=0 & \mathrm{x}=\mathrm{X} \forall y \forall t\end{cases} \\
& \left\{\begin{array}{l}
C_{1}=0 \\
C_{2}=0
\end{array}\right. \\
& \left\{\begin{array}{l}
-D_{h, 1} \nabla C_{1}+\vec{u} C_{1}=0 \\
-D_{h, 2} \nabla C_{2}+\vec{u} C_{2}=0
\end{array}\right.
\end{aligned}
$$

Where the notations 1 and 2 are relative to two species considered while $\mathrm{X}$ and $\mathrm{Y}$ correspond to the size of the computational domain respectively in the $\mathrm{x}$ - and $\mathrm{y}$-directions.

The procedure adopted for PAB-D optimization followed the method presented in previous papers (Santonastaso et al., 2018a; Di Nardo et al., 2014) and aimed at determining the minimum of both 
well diameter and number of wells (also corresponding to a minimum number of well lines and length of each well line), at the same time making sure to intercept and reduce the plume concentrations below the fixed thresholds by also minimizing the adsorbing material volume and remediation costs required.

\section{Case study}

The targeted aquifer to be remediated is located in an area of about $2.25 \mathrm{~km}^{2}$ in Giugliano in Campania, in the urban area north of Naples (Italy). In this area, over the past 20 years, about eight million tons of urban and special wastes were both legally and illegally disposed in several solid waste landfills present in the zone. Therefore many pollutants, both inorganic and organic, were released to the ground and found their way to reach the underlying aquifer, where considerable concentrations were measured. The aquifer is unconfined and placed in Neapolitan yellow tuff at a depth of about $40 \mathrm{~m}$ from the land surface (Bortone et al., 2013b).

Among the organic contaminants, benzene and toluene were detected at concentrations significantly higher than the corresponding Italian regulatory limits $\left(C_{l i m}\right)$, with peak values close to $9 \mu \mathrm{g} \mathrm{L}^{-1}$ for benzene $\left(C_{B-\text { lim }}=1 \mu \mathrm{g} \mathrm{L}^{-1}\right)$ and $60 \mu \mathrm{g} \mathrm{L}^{-1}$ for toluene $\left(C_{T \text {-lim }}=15 \mu \mathrm{g} \mathrm{L}^{-1}\right)$ respectively. The main characteristics of the aquifer are reported in Table 1.

The commercial activated carbon Filtrasorb 400, F400, from Calgon Carbon Corporation, whose characteristics are reported by Balsamo et al. (2013), was used to experimentally investigate the adsorption of the benzene/toluene system (Erto et al., 2017), for which the Eq. (6) can be written as follows:

$$
\omega_{1}=\omega_{1, M A X} \frac{K_{1} C_{1}^{*}}{1+K_{1} C_{1}^{*}+K_{2} C_{2}^{*}} \quad \omega_{2}=\omega_{2, M A X} \frac{K_{2} C_{2}^{*}}{1+K_{1} C_{1}^{*}+K_{2} C_{2}^{*}}
$$


Where the subscripts 1 and 2 are referred to benzene and toluene, respectively. The Langmuir parameters are $\omega_{1, \max }=1.13 \mathrm{mmol} \mathrm{g}{ }^{-1}, K_{l}=8.18 \cdot 10 \mathrm{~L} \mathrm{mmol}^{-1}, \omega_{2, \max }=1.49 \mathrm{mmol} \mathrm{g}^{-1}, K_{2}=8.18 \cdot 10^{2} \mathrm{~L}$ $\mathrm{mmol}^{-1}$ (Erto et al., 2017).

The initial distribution of contamination by benzene and toluene geographically located in the area, and the piezometric groundwater levels are reported in Figure 2 and Figure 3, respectively. In particular, both benzene and toluene concentrations, noted with $C_{B}$ and $C_{T}$, are shown using colour gradients, where red tones represent the highest concentrations, followed by yellow and green, which correspond to the limit concentrations, $C_{\text {lim }}$.

Table 1. Hydraulic and geological parameters of the area of investigation.

\begin{tabular}{lc}
\hline \multicolumn{2}{c}{ Aquifer characteristic } \\
\hline Computational area, $A$ & $2.25 \mathrm{~km}^{2}$ \\
Polluted area total extent, $A_{p}$ & $0.10 \mathrm{~km}^{2}$ \\
Aquifer average piezometric level, $H_{w}$ & $8 \mathrm{~m}$ \\
Piezometric gradient, $J$ & $0.01 \mathrm{~m} \mathrm{~m}^{-1}$ \\
Porosity, $n$ & 0.25 \\
Dry soil bulk density, $\rho$ & $1,400 \mathrm{~kg} \mathrm{~m}^{-3}$ \\
Hydraulic conductivity, $K_{s}$ & $5 \cdot 10^{-5} \mathrm{~m} \mathrm{~s}^{-1}$ \\
Longitudinal dispersivity, $\alpha_{x}$ & $1 \mathrm{~m}^{-1}$ \\
Transverse dispersivity, $\alpha_{y}$ & $0.1 \mathrm{~m}$ \\
Molecular diffusion coefficient Benzene, $D_{d, 1}^{*}$ & $1.17^{-9} \mathrm{~m}^{2} \mathrm{~s}^{-1}$ \\
Molecular diffusion coefficient Toluene, $D_{d, 2}^{*}$ & $1.29^{-9} \mathrm{~m}^{2} \mathrm{~s}^{-1}$ \\
\hline
\end{tabular}




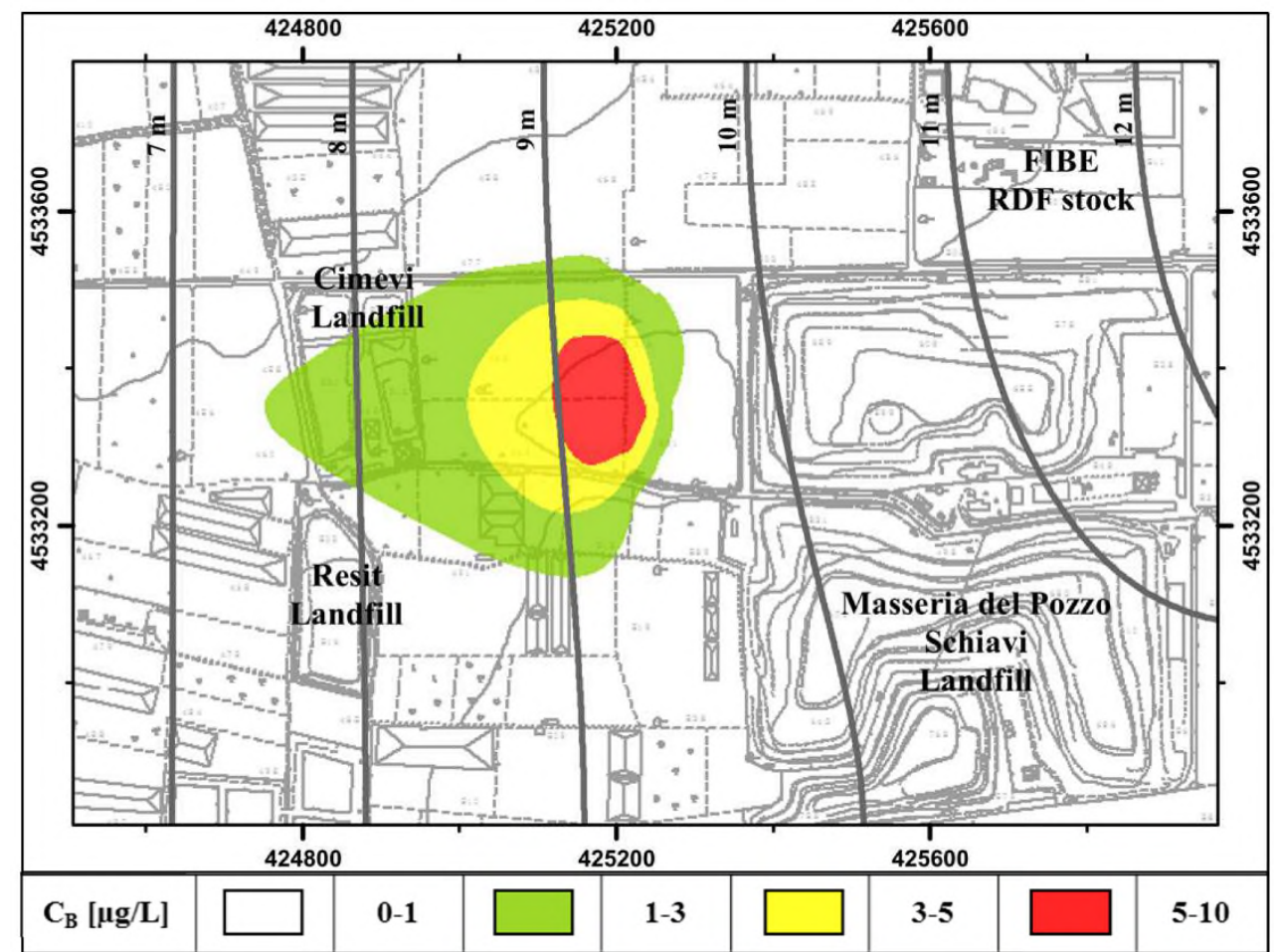

Figure 2. Benzene concentration, iso-concentration contours and piezometric levels for the area of investigation.

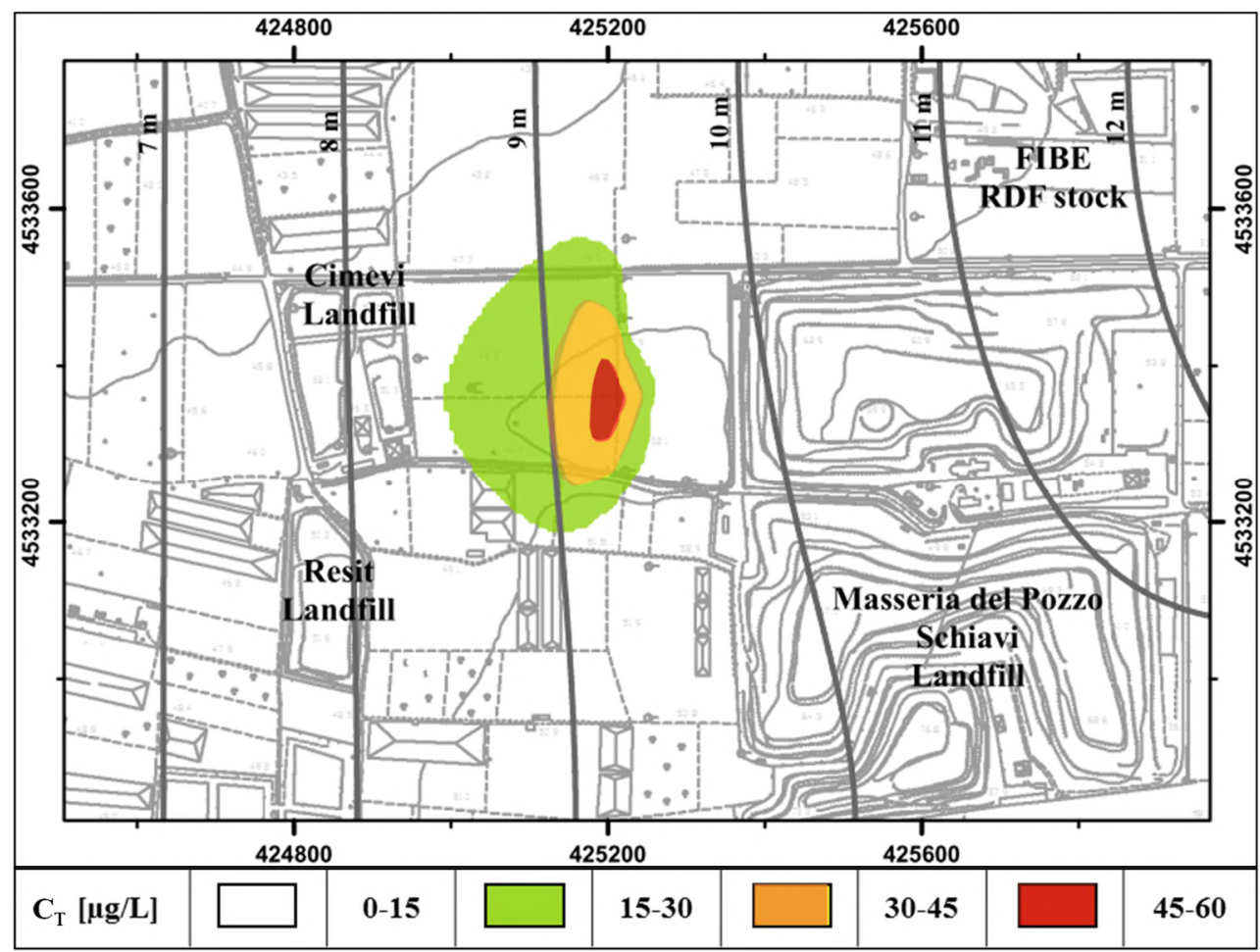

Figure 3. Toluene concentration, iso-concentration contours and piezometric levels for the area of investigation.

\section{Results and discussion}


After identifying the initial concentrations, numerous configurations trials identified the smallest configuration (count) of passive wells of specified diameter to remove the contaminant plume and prevent it from traveling downstream.

The geometric characteristics of the optimized well grid, including the height, $H$, and the length, $L$, of the optimal PAB-D, are summarized in Table 2. In particular, the well-to-well distance, $I$, and the line-to-line distance, $d_{c}$, were fixed equal to the well diameter, $D_{w}$ :

$I=D_{w}$

$d_{c}=D_{w}$

The optimization procedure was used to identify an optimal well diameter $\left(D_{w}\right)$ of $0.6 \mathrm{~m}$ and two PAB-D well lines $\left(n_{c}\right)$, with a total number of wells $\left(n_{w}\right)$ equal to 741 . In particular, the configuration included 541 wells in the first well line (Line 1) and 200 in the second line (Line 2) over a total length of $445 \mathrm{~m}$. The well-to-well distance $(I)$ and the line-to-line distance $\left(d_{c}\right)$ were equal to $0.6 \mathrm{~m}$, while the well height of the PAB-D was set equal to $8 \mathrm{~m}$.

Table 2. Optimized PAB-D configuration.

\begin{tabular}{ccccccccc}
\hline & \multicolumn{3}{c}{$n_{c}$} & & & & & \\
& \multirow{2}{*}{ Line 1 } & \multirow{2}{*}{ Line 2 } & $\begin{array}{c}n_{w} \\
{[-]}\end{array}$ & $\begin{array}{c}d_{c} \\
{[\mathrm{~m}]}\end{array}$ & $\begin{array}{c}I \\
{[\mathrm{~m}]}\end{array}$ & $\begin{array}{c}D_{w} \\
{[\mathrm{~m}]}\end{array}$ & $\begin{array}{c}H \\
{[\mathrm{~m}]}\end{array}$ & $\begin{array}{c}L \\
{[\mathrm{~m}]}\end{array}$ \\
\hline PAB-D & 541 & 200 & 741 & 0.6 & 0.6 & 0.6 & 8 & 445 \\
\hline
\end{tabular}

The benzene and toluene iso-concentrations as function of the simulation time, including the position of the PAB-D, are sketched in Figures 4(a) and (b). In particular the evolution of both the contaminants plumes after a simulation time of 5, 15 and 20 years are reported.

As shows, PAB-D allowed to intercept and capture the whole plume of both the contaminants, since at any simulation time the concentrations of benzene and toluene downstream of the barrier were lower than both contaminants threshold limits, $\left(C_{\text {lim }}\right)$ equal respectively to $1 \mu \mathrm{g} \mathrm{L}^{-1}\left(C_{B-\text { lim }}\right)$ and $15 \mu \mathrm{g} \mathrm{L}-1\left(C_{T-l i m}\right)$ 
Breakthrough curves for benzene and toluene are sketched in Figures 5 and 6, respectively. These curve lines illustrate the pollutant concentration over the simulation time at the PAB-D inlet $\left(C_{i n}\right)$, where the highest pollutant concentration were detected, and the corresponding PAB-D outlet $\left(C_{\text {out }}\right)$, along with the aquifer flow direction. In particular, $C_{\text {lim }}$ was represented with a solid red line while $C_{\text {in }}$ and $C_{\text {out }}$ with respectively a blue and a black solid line. 
(a) Benzene

$\mathrm{t}-=\mathbf{5}$ years

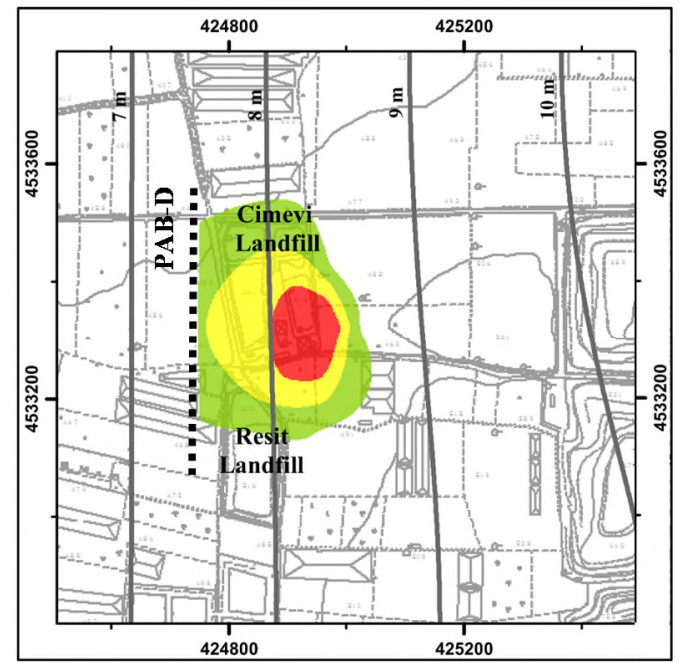

$\mathbf{t}-\mathbf{1 5}$ years

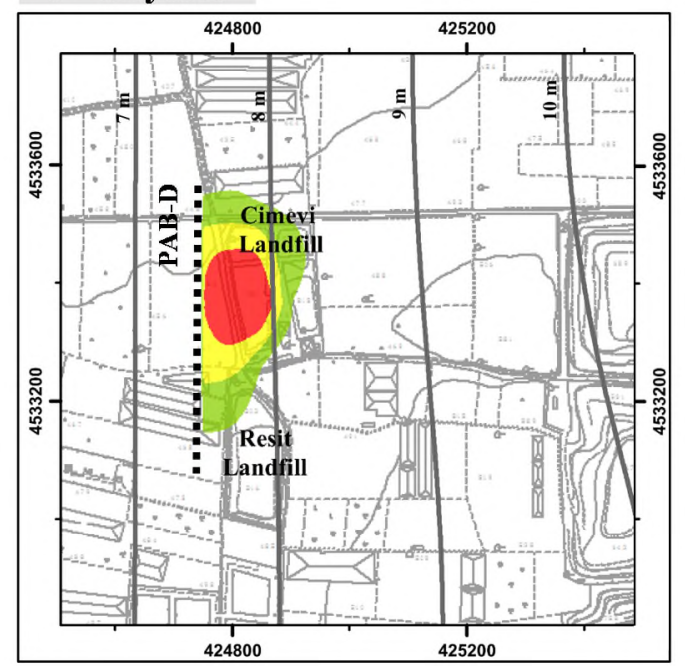

$\mathrm{t}-\mathbf{2} \mathbf{2 0}$ years

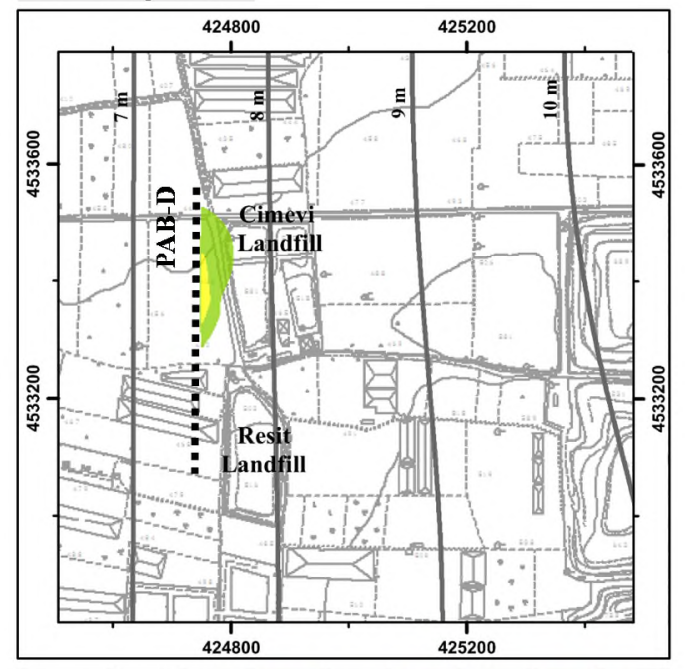

\begin{tabular}{|l|l|l|l|l|l|l|l|l|}
\hline $\mathrm{C}_{\mathrm{B}}[\mathrm{Hg} /]$ & $\square$ & 0.1 & $\square$ & 1.3 & $\square$ & 3.5 & $\square$ & 5.10 \\
\hline
\end{tabular} (b) Toluene
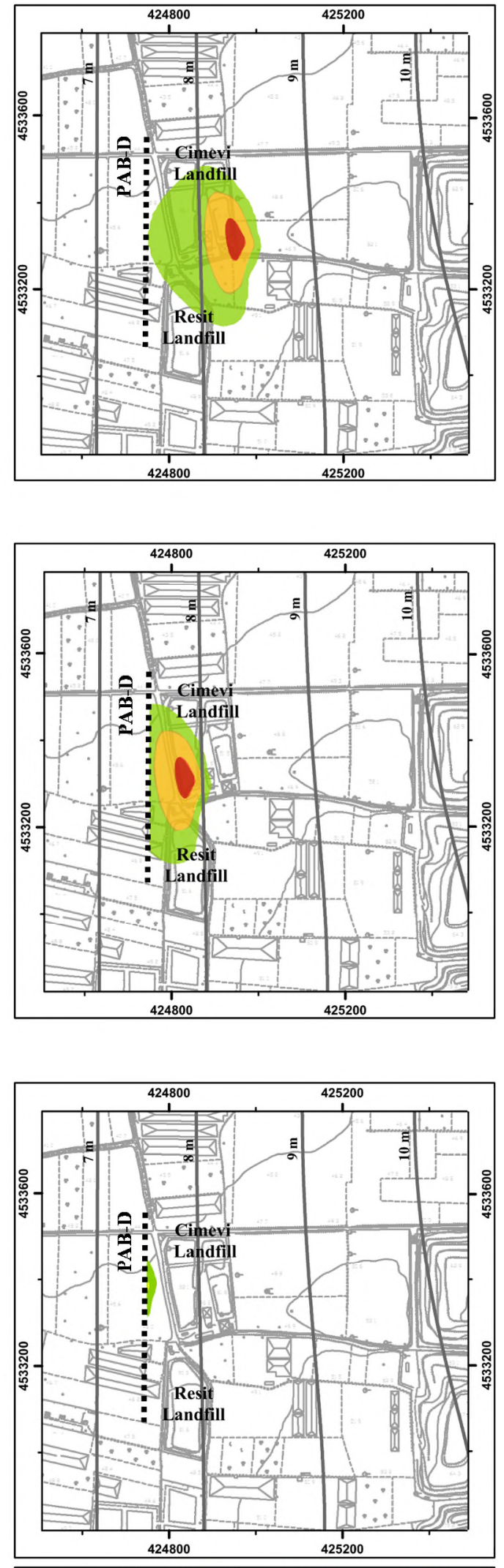

\begin{tabular}{|l|l|l|l|l|l|l|l|l|l|}
\hline $\mathrm{C}_{\mathrm{T}}[\operatorname{lng}[\mathrm{L}[\mathrm{I}$ & $\square$ & 0.15 & $\square$ & 15.30 & $\square$ & 30.45 & $\square$ & 45.60 \\
\hline
\end{tabular}

Figure 4. Position of the schematized PAB-D and its effect on benzene (a) and toluene (b) isoconcentration as function of simulation time after respectively 5, 15 and 20 years. 


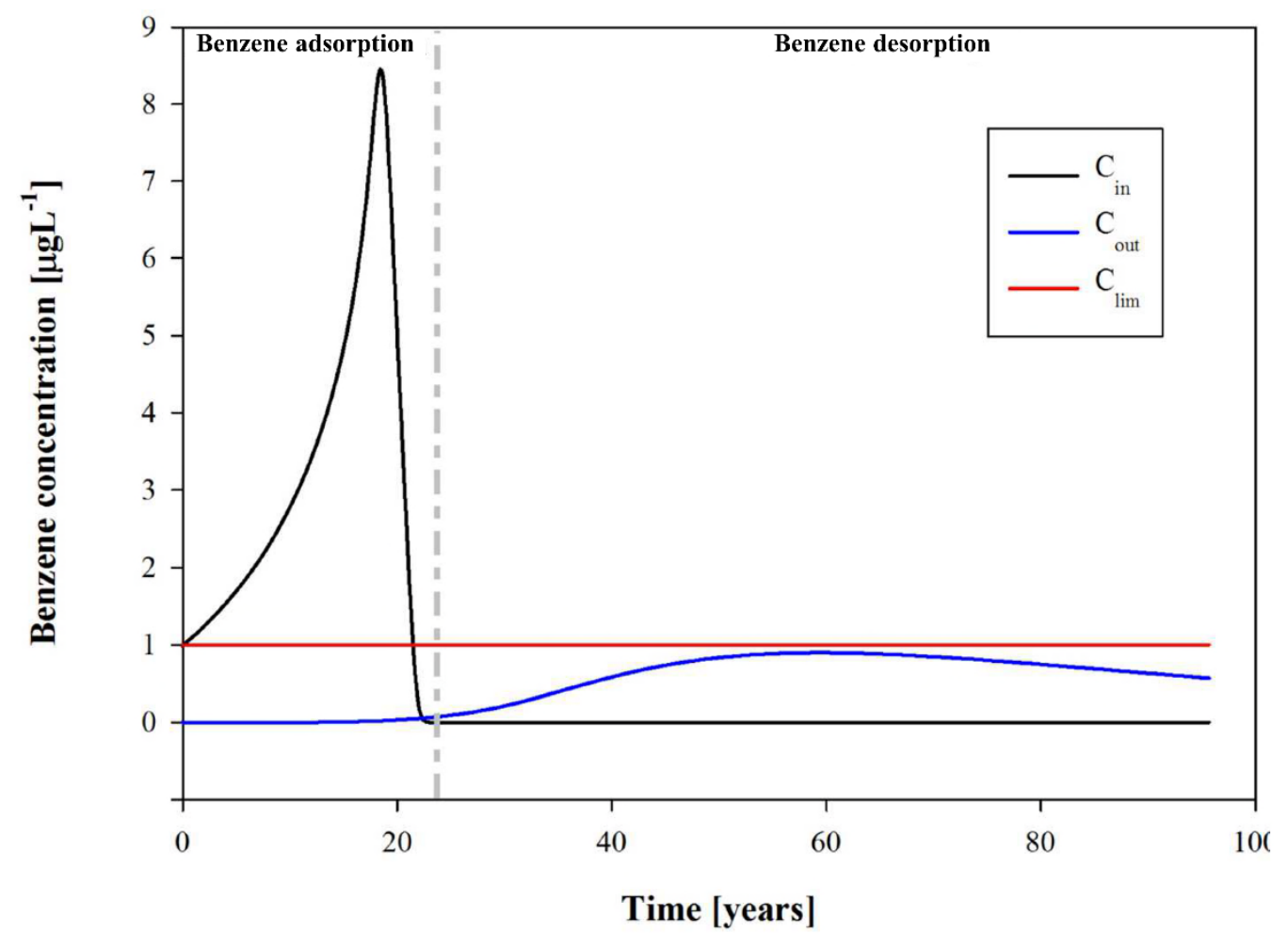

Figure 5. Breakthrough curves for benzene concentration at the inlet $\left(C_{\text {in }}\right)$ and at the outlet $\left(C_{\text {out }}\right)$ of the barrier. The Italian regulatory limit $\left(C_{\text {lim }}\right)$ for benzene is indicated.

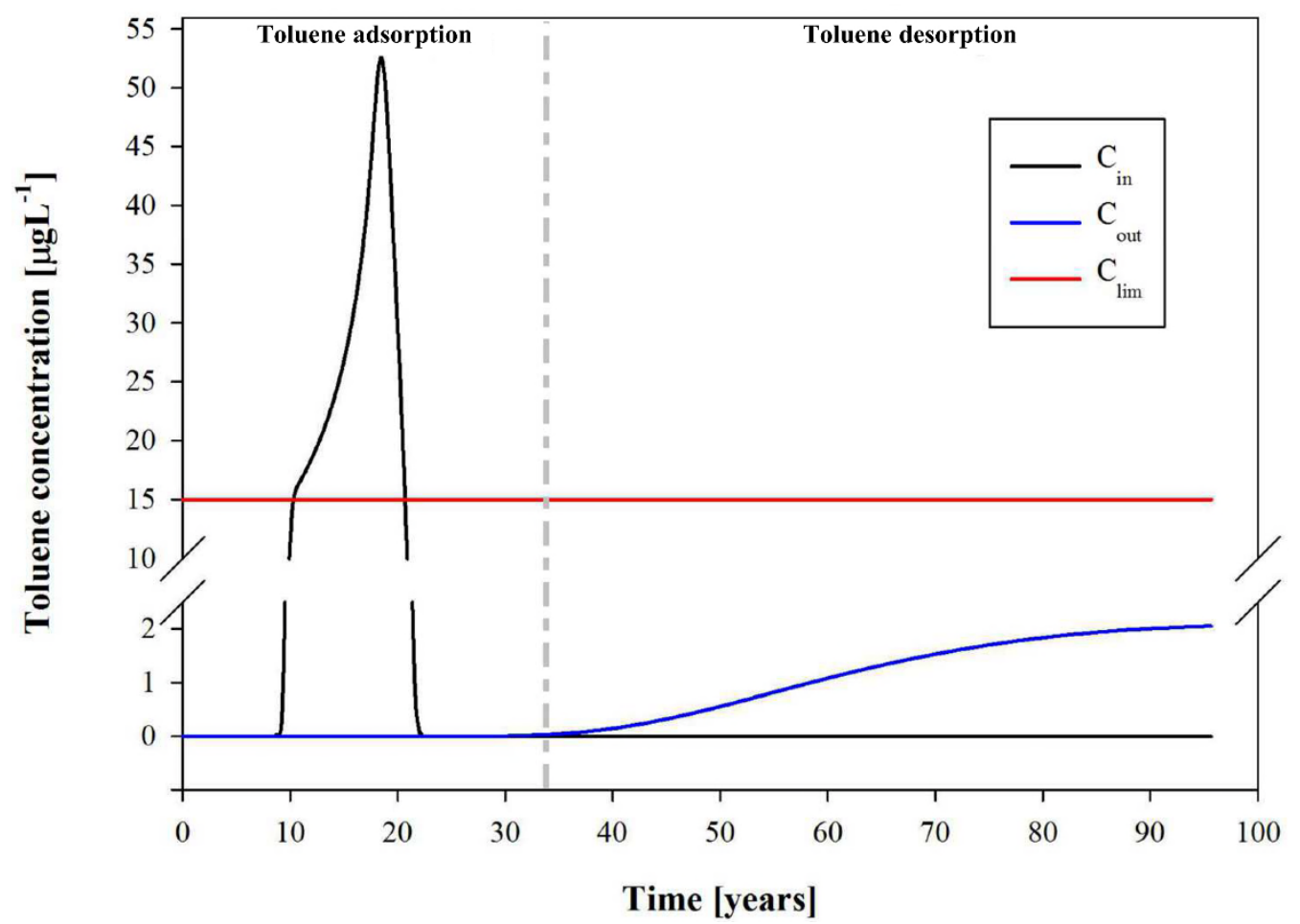

Figure 6. Breakthrough curves for toluene concentration at the inlet $\left(C_{\text {in }}\right)$ and at the outlet $\left(C_{\text {out }}\right)$ of the barrier. The Italian regulatory limit $\left(C_{\text {lim }}\right)$ for toluene is indicated. 
As shown, the peaks of inlet concentrations of benzene and toluene required about 19 years to reach the barrier, while a total time of about 21 years was necessary to capture both the plumes, during which the outlet concentrations of both the compounds were detected as lower than the regulatory limits in the whole domain.

After the contaminants capture, desorption phenomena were investigated by considering the outlet concentrations of benzene and toluene over the simulation time. In particular, during a simulation time of 100 years, benzene outlet concentration achieved a maximum lower than the regulatory limit after which the concentration decreased. For toluene outlet concentration, a monotonic trend of outlet concentration was found and, also in this case, the maximum reached resulted lower than the toluene regulatory limit. In conclusion, for both pollutants, the concentrations at the outlet of the barrier during both adsorption and desorption phenomena resulted lower than $C_{\text {lim }}$.

The simulation results highlight the effectiveness of the optimized PAB-D for the remediation of the aquifer simultaneously contaminated by aromatic hydrocarbons, which is also able to assure the absence of desorption of captured pollutants in concentrations higher than the corresponding regulatory limits. Moreover, it is important observing that at the end of the remediation time the activated carbon can be left in the site, being a guard for further contamination phenomena possibly occurring.

Finally, the PAB-D was compared with a PAB-C designed for the remediation of the same area of investigation, in terms of the volume of adsorbing material $\left(\mathrm{V}_{\mathrm{ad}}\right)$ and remediation cost $\left(\mathrm{C}_{\mathrm{R}}\right)$, whose results are stated in Tables 3 and 4.

The remediation costs $\left(C_{R}\right)$ were calculated by adding the PAB-D drilling cost $\left(C_{w e l l}\right)$, the adsorbing material cost $\left(\mathrm{C}_{\mathrm{Ad}}\right)$ and the monitoring cost $\left(\mathrm{C}_{\mathrm{M}}\right)$, whose corresponding unit values considered are listed in Table 3 (Santonastaso et al., 2018a). It is worth highlighting that, being PABs a passive technology, operating and maintenance costs were neglected (Santonastaso et al., 2018a).

Table 4 summarises the optimal dimensions and the corresponding costs obtained for both PAB-D and PAB-C, where cost and volume variances were also estimated and indicated as $\Delta \mathrm{V}_{\mathrm{ad}}$ and $\Delta \mathrm{C}_{\mathrm{R}}$, 
respectively. The total volume $\left(\mathrm{V}_{\mathrm{ad}}\right)$ of both $\mathrm{PAB}-\mathrm{D}$ and $\mathrm{PAB}-\mathrm{C}$ was calculated via multiplying their correspondent width, $(W)$, by their length $(L)$ and height $(H)$. In particular, for PAB-D, $W$ was set equal to $D_{w}$ (Figure $1 \mathrm{~b}$ ), while $L$ was calculated by multiplying the total number of wells $\left(n_{w}\right)$ by the PAB-D width or diameter $(W)$.

As shown, the optimal PAB-D total volume $\mathrm{V}_{\text {ad }}$ resulted equal to $2,136 \mathrm{~m}^{3}$, allowing to save up to $49 \%$ of the adsorbing material quantity, when compared to the optimal PAB-C obtained for the same targeted area. Accordingly, the related material and drilling costs $\left(\mathrm{C}_{\text {well }}\right.$ and $\left.\mathrm{C}_{\mathrm{Ad}}\right)$ were also considerably reduced, accomplishing a remediation cost decrease of about 35\% (Table 4).

Table 3. PAB-D and PAB-C unit costs (Santonastaso et al., 2018a)

\begin{tabular}{ccccc}
\hline \multirow{2}{*}{ PAB-D } & & $\mathbf{C}_{\text {well }}$ & $\mathbf{C}_{\text {Ad }}$ & $\mathbf{C M}_{\mathbf{M}}$ \\
\cline { 2 - 5 } & $D_{w}[\mathrm{~m}]$ & Unit cost $\left[€ \mathrm{~m}^{-1}\right]$ & Unit $\operatorname{cost}\left[€ / \mathrm{m}^{3} \mathrm{Ad}\right]$ & {$[\mathrm{k} €]$} \\
\cline { 2 - 5 } & 0.6 & 51 & 780 & 250 \\
\hline \multirow{3}{*}{ PAB-C } & & $\mathbf{C}_{\text {barrier }}$ & $\mathbf{C}_{\text {Ad }}$ & $\mathbf{C M}_{\mathbf{M}}$ \\
\cline { 2 - 5 } & Thickness $[\mathrm{m}]$ & Unit cost $\left[€ \mathrm{~m}^{-1}\right]$ & Unit $\operatorname{cost}\left[€ / \mathrm{m}^{3} \mathrm{Ad}\right]$ & {$[\mathrm{k} €]$} \\
\cline { 2 - 5 } & 0.8 & 57 & 780 & 250 \\
\hline
\end{tabular}

Table 4. Comparison between adsorbing material volume and remediation cost for PAB-D and PAB-C.

\begin{tabular}{cccccccccccccc}
\hline & \multicolumn{2}{c}{$\boldsymbol{n}_{\boldsymbol{c}}$} & $\boldsymbol{n}_{\boldsymbol{w}}$ & $\boldsymbol{H}$ & $\boldsymbol{W}$ & $\boldsymbol{L}$ & $\mathbf{V}_{\text {ad }}$ & $\boldsymbol{\Delta} \mathbf{V}_{\text {ad }}$ & $\mathbf{C}_{\mathbf{W e l l}}$ & $\mathbf{C}_{\mathbf{A d}}$ & $\mathbf{C}_{\mathbf{M}}$ & $\mathbf{C}_{\mathbf{R}}$ & $\boldsymbol{\Delta} \mathbf{C}_{\mathbf{R}}$ \\
\hline & Line1 & Line2 & & {$[\mathrm{m}]$} & {$[\mathrm{m}]$} & {$[\mathrm{m}]$} & {$\left[\mathrm{m}^{3}\right]$} & {$[\mathbf{\%}]$} & {$[\mathrm{k} €]$} & {$[\mathrm{k} €]$} & {$[\mathrm{k} €]$} & {$[\mathrm{k} €]$} & {$[\%]$} \\
\hline PAB-D & 541 & 200 & 741 & 8 & 0.6 & 445 & 2,136 & \multirow{2}{*}{$\mathbf{4 9}$} & 1,813 & 1,666 & 250 & 3,729 & \multirow{3}{*}{} \\
PAB-C & & & & 8 & 0.8 & 650 & 4,160 & & 2,223 & 3,244 & 250 & 5,717 & \\
\hline
\end{tabular}

\section{Conclusions}

In this paper, an optimized configuration of a discontinuous Permeable Adsorptive Barrier (PAB-D) for the remediation of an aquifer simultaneously contaminated by benzene and toluene was presented. The results of the numerical simulations showed that PAB-D is an effective in-situ remediation technique, offering both to restore contaminated aquifers by aromatic hydrocarbons in case of multiple contamination, and to overcome a possible desorption of the captured pollutants. The best array configuration of PAB-D resulted made of 741 wells, each having a diameter of $0.6 \mathrm{~m}$. Moreover, 
a further analysis, which compared the designed PAB-D with a continuous configuration (PAB-C), highlighted that PAB-D allows to further reduce both total adsorbing material volume and remediation cost, which for the case study resulted lessened respectively of $49 \%$ and $35 \%$. In brief, the results reported in the present paper emphasize how passive adsorptive wells can be considered as a cost-effective and efficient alternative to the most frequently used continuous scheme for groundwater remediation, also when a multiple contamination occurs.

\section{References}

ATSDR (2007) Toxicological Profile for Benzene. Agency Toxic Subst Dis Regist, pp. 438

ATSDR (2015) Toluene. Full SPL data. Substance priority list (SPL) resource page. Agency for Toxic Substances and Disease Registry, Centers for Disease Control and Prevention. http://www.atsdr.cdc.gov/SPL/resources/index.html. August 26, 2016

Balsamo M, Rodríguez-Reinoso F, Montagnaro F, et al (2013) Highlighting the Role of Activated Carbon Particle Size on CO2 Capture from Model Flue Gas. Ind Eng Chem Res 52:1218312191. https://doi: 10.1021/ie4018034

Bear J (1979) Hydraulics of Groundwater. New York.

Bortone I, Chianese S, Di Nardo A, et al (2013a) A comparison between Pump \& Treat technique and permeable reactive barriers for the remediation of groundwater contaminated by chlorinated organic compounds. Chem Eng Trans, 32:31-36

Bortone I, Di Nardo A, Di Natale M, et al (2013b) Remediation of an aquifer polluted with dissolved tetrachloroethylene by an array of wells filled with activated carbon. J Hazard Mater 260:914920. https://doi: 10.1016/j.jhazmat.2013.06.050

Bortone I, Erto A, Santonastaso G, et al (2015) Design of Permeable Adsorptive Barriers (PABs) for groundwater remediation by COMSOL Multi-physics simulations. Desalin Water Treat 55:3231-3240. https://doi: 10.1080/19443994.2014.957931

Caetano MO, Schneider IAH, Gomes LP, Kieling AG, Miranda LAS (2017) A compact remediation system for the treatment of groundwater contaminated with BTEX and TPH. Environ Technol 
38(11),1408-1420. https://doi: 10.1080/09593330.2016.1231222

Canzano S, Capasso S, Di Natale M, et al (2014) Remediation of groundwater polluted by aromatic compounds by means of adsorption. Sustain 6:4807-4822. https://doi: 10.3390/su6084807

Carpenter P J, Ding A, Cheng L (2012) Identifying Groundwater Contamination Using Resistivity Surveys at a Landfill near Maoming, China. Nat Educ Knowl 3(6):23

Chen L, Liu F, Liu YL, et al (2011) Benzene and toluene biodegradation down gradient of a zerovalent iron permeable reactive barrier. J Hazard Mater 188:110-115. https://doi: 10.1016/j.jhazmat.2011.01.076

Chen C, Binh N, Hung C, et al (2016). Removal of Polycyclic Aromatic Hydrocarbons from Sediments using Chemical Oxidation Processes. J Adv Oxid Technol 18(1):15-22. https://doi:10.1515/jaots-2015-0102

Cole GM (1994) Assessment and Remediation of Petroleum Contaminated Sites. CRC Press. Boca Raton, Florida

Di Nardo A, Bortone I, Di Natale M, et al (2014) A heuristic procedure to optimize the design of a permeable reactive barrier for in situ groundwater remediation. Adsorpt Sci Technol 32:125140. https://doi: 10.1260/0263-6174.32.2-3.125

EPA (1993) Selecting Remediation Techniques for Contaminated Sediment, EPA-823-B93-C01. Washington DC, Office of Water. http://www.epa.gov/waterscience/library/sediment/rem ediation.pdf.

Erto A, Lancia A, Bortone I, et al (2011) A procedure to design a Permeable Adsorptive Barrier (PAB) for contaminated groundwater remediation. J Environ Manage 92:23-30.

Erto A, Bortone I, Di Nardo A, et al (2014) Permeable Adsorptive Barrier (PAB) for the remediation of groundwater simultaneously contaminated by some chlorinated organic compounds. J Environ Manage 140:111-119. https://doi: 10.1016/j.jenvman.2014.03.012

Erto A, Chianese S, Lancia A, Musmarra D (2017) On the mechanism of benzene and toluene adsorption in single-compound and binary systems: Energetic interactions and competitive 
effects. Desalin Water Treat 86:259-265. https://doi: 10.5004/dwt.2017.20712

Gao W, Zhang Y, Zhang X, et al (2015) Permeable reactive barrier of coarse sand-supported zero valent iron for the removal of 2,4-dichlorophenol in groundwater. Environ Sci Pollut Res 22:16889-16896. https://doi: 10.1007/s11356-015-4912-x

Gelhar LW, Welty C, Rehfeldt KR (1992) A critical review of data on field-scale dispersion in aquifers. Water Resour Res 28:1955-1974. https://doi: 10.1029/92WR00607

IARC (2013) Agents classified by the IARC monographs. Volumes 1-109. Lyon, France: International for Agency on Cancer. http://monographs.iarc.fr/ENG/Classification/index.php. January 08, 2014.

Lahvis MA, Baehr AL, Baker RJ (1999) Quantification of aerobic biodegradation and volatilization rates of gasoline hydrocarbons near the water table under natural attenuation conditions. Water Resour Res 35 (3):753-765.

LD (2006) Legislative Decree 152/2006 (Environmental Protection Code) Testo Unico Ambientale 152/2006. Available online: https://www.camera.it/parlam/leggi/deleghe/06152dl2.htm (accessed on 9 May 2019) (in italian)

Lee S, Yun Y, Kim DG (2017) Nitrate reduction by micro-scale zero-valent iron particles under oxic condition. KSCE J Civ Eng 21:2119-2127 . https://doi: 10.1007/s12205-017-1701-8

Leone V, Capasso S, Chianese S, et al (2018) Sorption of benzene derivatives onto a humic acidzeolitic tuff adduct. Environ Sci Pollut Res 25(27):26831-26836. https://doi: 10.1007/s11356018-1540-2

Liang C, Chen YJ (2010) Evaluation of activated carbon for remediating benzene contamination: Adsorption and oxidative regeneration. J Hazard Mater 182:544-551. https://doi: 10.1016/j.jhazmat.2010.06.066

Liu S, Yang Q, Yang Y, et al (2017) In situ remediation of tetrachloroethylene and its intermediates in groundwater using an anaerobic/aerobic permeable reactive barrier. Environ Sci Pollut Res 24:26615-26622. https://doi: I 10.1007/s11356-017-0290-x 
Luo X, Liu H, Huang G, et al (2016) Remediation of arsenic-contaminated groundwater using mediainjected permeable reactive barriers with a modified montmorillonite: sand tank studies. Environ Sci Pollut Res 23:870-877. https://doi: 10.1007/s11356-015-5254-4

Mitra S, Roy P (2011) BTEX : A Serious Ground-water Contaminant. Res J Environ Sci 5:394-398. https://doi: 10.3923/rjes.2011.394.398

Polonski M, Pawluk K, Rybka I (2017) Optimization Model for the Design of Multi-layered Permeable Reactive Barriers. IOP Conference Series: Mater Sci Eng. 245, 072017 https://doi:10.1088/1757-899X/245/7/072017

Powell RM, Puls RW, Blowes DW, et al (1998) Permeable Reactive Barrier Technologies for Contaminant Remediation. US Environmental Protection Agency, Report, EPA/600/R-98/125, Washington DC

Pryor RW (2011) Multiphysics Modeling Using COMSOL®. A First Principles Approach. pp. 700. ISBN: 9781936420094

Reeter C, Chao S, Gavaskar A (1999) Permeable Reactive Wall Remediation of Chlorinated Hydrocarbons in Groundwater. US Department of Defense, Environmental Security Technology Certification Program (ESTCP), ESTCP Cost and Performance Report

Santonastaso GF, Bortone I, Chianese S, et al (2016) Application of a discontinuous permeable adsorptive barrier for aquifer remediation. A comparison with a continuous adsorptive barrier. Desalin Water Treat 57:23372-23381. https://doi: 10.1080/19443994.2015.1130921

Santonastaso GF, Bortone I, Chianese S, et al (2018a) Discontinuous permeable adsorptive barrier design and cost analysis: a methodological approach to optimisation. Environ Sci Pollut Res. 25, (27):26793-26800. https://doi: 10.1007/s11356-017-0220-y

Santonastaso GF, Erto A, Bortone I, et al (2018b) Experimental and simulation study of the restoration of a thallium (I)-contaminated aquifer by Permeable Adsorptive Barriers (PABs). Sci Total Environ 630: 62-71 .https://doi: 10.1016/j.scitotenv.2018.02.169

Tabatabaian M (2014) COMSOL® for Engineers. British Columbia Institute of Technology, pp. 254. 
ISBN: 978-1-938549-53-3

Thiruvenkatachari R, Vigneswaran S, Naidu R (2008) Permeable reactive barrier for groundwater remediation. J Ind Eng Chem 14:145-156

US EPA (1986) Test Methods for Evaluating Solid Waste. IA.SW-846. 3rd edn. United States Environmental Protection Agency, Washington, DC, USA 